\title{
EDITORIAL
}

The completion of this the first volume finds Géotechnique firmly established as an international journal of Soil Mechanics research, with subscribers in many countries. The articles so far published have covered a wide field, but with emphasis on a problem of great technical difficulty and much practical importance, viz., the shear strength of clay.

Correspondence on a controversial subject, the Ultimate Bearing Capacity of Foundations, has produced valuable field observations and made it clear that Géotechnique has filled a real need of the engineering profession.

With the establishment of the National Committees of the International Conference of Soil Mechanics and Foundation Engineering at Rotterdam in 1948, it was agreed by the Founder Members of the Geotechnical Society that although the Society had performed a useful function in the immediate post-war years it was now redundant and a letter was sent by them to the Secretary of the Institution of Civil Engineers, who had appointed the British National Committee for the 1948 Conference, proposing that the journal should be transferred to and published by that Institution. The Council of the Institution gave their assent. The production of the journal will in future be assisted by a Géotechnique Advisory Panel appointed by the Institution of Civil Engineers.

Under this new arrangement, there will be no changes in the policy of the journal, its general character will remain unaltered and articles will continue to be published in English or French.

In future, correspondence should be addressed to "Géotechnıque," The Institution of Cir il Engineers, Great George Street, London, S.W.1.

The present editors wish to take this opportunity to thank their colleagues in many countries for their support during the last two years, and the Council of the Institution of Civil Engineers for their action in supporting the continued publication of the journal.

Subscription forms and/or Bankers' Order forms in favour of the I.C.E. accompany this number.

\section{BIBLIOGRAPHY ON SOIL MECHANICS}

In view of the number of requests received for copies of the "Bibliography on Soil Mechanics," it has been decided to publish it, and copies will be available from the Institution of Civil Engineers on January 15, 1950. The price, $£ 33$ s., post free.

The Bibliography contains 3,000 references to papers and articles on Soil Mechanics published between 1920 and 1946, with a few important items published earlier than 1920 .

The references have been classified by the Universal Decimal System, and arranged both in U.D.C. order and alphabetical order of authors.

The Bibliography will be bound in loose-leaf form to allow for additional entries ; in this connection it is intended to publish supplements from time to time. 